\title{
Fasting and Postprandial Hyperglycemia: Their Predictors and Contributions to Overall Hyperglycemia in Korean Patients with Type 2 Diabetes
}

\author{
Jaecheol Moon ${ }^{1, *}$, Ji Young Kim ${ }^{1, *}$, Soyeon Yoo $^{1,2}$, Gwanpyo Koh ${ }^{1,2}$ \\ ${ }^{1}$ Department of Internal Medicine, Jeju National University Hospital; ${ }^{2}$ Department of Internal Medicine, Jeju National \\ University School of Medicine, Jeju, Korea
}

Background: This study aimed to identify factors that affect fasting hyperglycemia (FHG) and postprandial hyperglycemia (PPG) and their contributions to overall hyperglycemia in Korean patients with type 2 diabetes mellitus (T2DM).

Methods: This was a retrospective study conducted on 194 Korean T2DM patients with 7-point self-monitoring blood glucose (SMBG) profiles plotted in 4 days in 3 consecutive months. We calculated the areas corresponding to FHG and PPG (area under the curve $[\mathrm{AUC}]_{\mathrm{FHG}}$ and $\mathrm{AUC}_{\mathrm{PPG}}$ ) and contributions (\%) in the graph of the 7-point SMBG data. The levels of glycated hemoglobin (HbA1c) were categorized by tertiles, and the contributions of FHG and PPG were compared.

Results: The relative contribution of FHG increased $(44.7 \% \pm 5.6 \%, 58.0 \% \pm 4.4 \%, 66.5 \% \pm 2.8 \%$; PANOVA $=0.002, P$ TREND $<0.001)$, while that of PPG decreased $(55.3 \% \pm 5.5 \%, 42.0 \% \pm 4.4 \%, 33.5 \% \pm 2.8 \%$; PANOVA $=0.002, P$ TREND $<0.001)$ with the elevated $\mathrm{HbAlc}$. Multivariate analysis showed that $\mathrm{HbA1c}(\beta=0.615, P<0.001)$, waist circumference $(\beta=0.216, P=0.042)$, and triglyceride $(\beta=0.121, P=0.048)$ had a significant association with $\mathrm{AUC}_{\mathrm{FHG}}$. Only HbAlc $(\beta=0.231, P=0.002)$ and age $(\beta=0.196$, $P=0.009)$ was significantly associated with AUC $C_{\text {PPG. }}$.

Conclusion: The data suggested that in Korean T2DM patients, FHG predominantly contributed to overall hyperglycemia at higher $\mathrm{HbAlc}$ levels, whereas it contributed to PPG at lower HbAlc levels. It is recommended that certain factors, namely age, degree of glycemic control, obesity, or triglyceride levels, should be considered when prescribing medications for T2DM patients.

Keywords: Hyperglycemia; Fasting; Glycated hemoglobin A

\section{INTRODUCTION}

Various research and debates have been conducted about whether glycated hemoglobin (HbAlc) - an index for the overall hyperglycemia - is more related to fasting hyperglycemia (FHG) or postprandial hyperglycemia (PPG). In 1997, Avignon et al. [1] first measured blood glucose at different times of the day to

Received: 1 January 2020, Revised: 15 February 2020, Accepted: 1 April 2020 Corresponding author: Gwanpyo Koh

Department of Internal Medicine, Jeju National University School of Medicine, 15 Aran 13-gil, Jeju 63241, Korea

Tel: +82-64-754-8163, Fax: +82-64-717-1131, E-mail: okdom@jejunu.ac.kr

*These authors contributed equally to this work. study the relative effect of FHG and PPG on HbA1c. They found that PPG was a better predictor of overall hyperglycemia than FHG. Analyzing the diabetes control and complication trial (DCCT) data, Rohlfing et al. [2] also showed that PPG had a linear association with $\mathrm{HbAlc}$ and had a stronger association with overall hyperglycemia than FHG. In contrast, Bonora et al. [3] reported that FHG had a stronger association with overall

\section{Copyright $\odot 2020$ Korean Endocrine Society}

This is an Open Access article distributed under the terms of the Creative Commons Attribution Non-Commercial License (https://creativecommons.org/ licenses/by-nc/4.0/) which permits unrestricted non-commercial use, distribution, and reproduction in any medium, provided the original work is properly cited. 
hyperglycemia than PPG.

To re-examine these associations, Monnier et al. [4] had patients with type 2 diabetes mellitus (T2DM) blood glucose measured at four points of time and calculated the area under the blood glucose curve. In their study, the contribution of PPG to overall hyperglycemia was high in the group with relatively good blood glucose control, while that of FHG increased with poorer blood glucose control.

Following the study by Monnier et al. [4], several other investigations were conducted using the same method. For example, the study by Riddle et al. [5] classified targets according to HbAlc in the same way as Monnier et al. [4] and recognized the contribution of FHG and PPG. The authors also categorized participants by $\mathrm{HbAlc}$ into the same groups as in the study by Monnier et al. [4] and examined the contributions of FHG and PPG. They pointed out that the contribution of FHG in all groups was $70 \%$ or greater. Furthermore, despite a slight rise in the contribution of FHG as HbA1c increased, no statistically significant difference was observed.

Previous studies have shown conflicting results despite using the same analysis methods, and only a few studies have been carried out on Asian populations. Therefore, we conducted this study aiming to do the following: (1) examine how the contribution of FHG and PPG changes with HbA1c in Korean T2DM patients and (2) analyze the factors, other than HbAlc, associated with FHG and PPG.

\section{METHODS}

\section{Participants}

In this study, we retrospectively collected and analyzed the data of patients visiting the outpatient clinic in the Division of Endocrinology and Metabolism, Department of Internal Medicine, Jeju National University Hospital, from August 2009 to October 2011. The patients must meet the inclusion criteria as follows: (1) they suffered from T2DM; (2) their age range must be between 20 and 80 years old; and (3) they had performed 7-point self-monitoring blood glucose (SMBG), i.e., had recorded their own blood glucose levels seven times a day, for 4 days (sessions) as recommended by a medical professional. Days 1, 2, and 3 were in the beginning of the first, second, and third months, respectively, while day 4 was at the end of the third month (Fig. 1).

Patients were excluded from the study if (1) they had type 1 diabetes (serum C-peptide $<0.6 \mathrm{ng} / \mathrm{mL}$ or increased anti-glutamic acid decarboxylase antibody titer, if they received multiple doses of insulin from the time of diagnosis, or if they had a

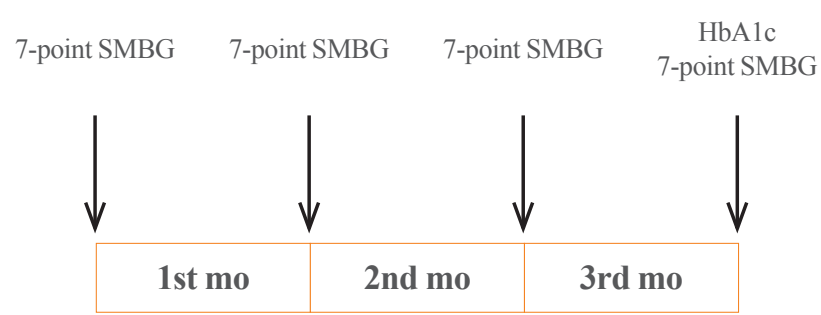

Fig. 1. Measurement of seven-point self-monitoring of blood glucose (SMBG) and glycated hemoglobin (HbAlc).

history of diabetic ketoacidosis); and (2) they were administered insulin or $\alpha$-glucosidase inhibitors. They were excluded because the medications can have certain effects on PPG. After applying the inclusion and exclusion criteria, we had a final sample of 194 patients.

This study was approved by the Institutional Review Board of the Jeju National University Hospital (IRB File No. JEJUNUH 2015-06-006) and was exempted from informed consent requirements because of its retrospective nature.

\section{Study procedure}

All participants performed 7-point SMBG immediately before each meal, 2 hours after each meal, and before sleeping. The recording of SMBG was conducted for 4 days (sessions) selected in the 3 consecutive months. In the last session, HbAlc was also measured (Fig. 1).

Using 7-point SMBG profiles, we calculated the area under the curve (AUC). The $\mathrm{AUC}_{\text {total }}$ was defined as the area that corresponds to $5.6 \mathrm{mmol} / \mathrm{L}(100 \mathrm{mg} / \mathrm{dL})$ or greater. We used 100 $\mathrm{mg} / \mathrm{dL}$ as the cut-off point because it is defined as the upper limit of normal fasting glucose by the American Diabetes Association [6]. $\mathrm{AUC}_{\mathrm{FHG}}$ was calculated by $\mathrm{AUC}_{\text {total- }}-\mathrm{AUC}_{\mathrm{PPG}}$, and the contribution of $\mathrm{FHG}$ was $\mathrm{AUC}_{\mathrm{FHG}} / \mathrm{AUC}_{\text {total }}(\%)$. $\mathrm{AUC}_{\mathrm{PPG}}$ refers to the area above the fasting glucose level in the graph, and the contribution of PPG on the overall hyperglycemia was calculated by $\mathrm{AUC}_{\mathrm{PPG}} / \mathrm{AUC}_{\text {total }}(\%)$ (Fig. 2). We used these calculations (i.e., the mean values of contribution) to identify the association between FHG and PPG with HbAlc. We divided the patients into three groups according to HbA1c tertiles: Group 1 (6.6\% or below), Group 2 (6.7\% to 7.1\%), and Group 3 (7.2\% or above). The mean contributions of FHG and PPG were then compared among the three groups.

Demographic characteristics, medical history, and the history of hypoglycemic agent use were investigated through interviews and electronic medical records, and physical examinations were performed by a physician. Some blood tests were 


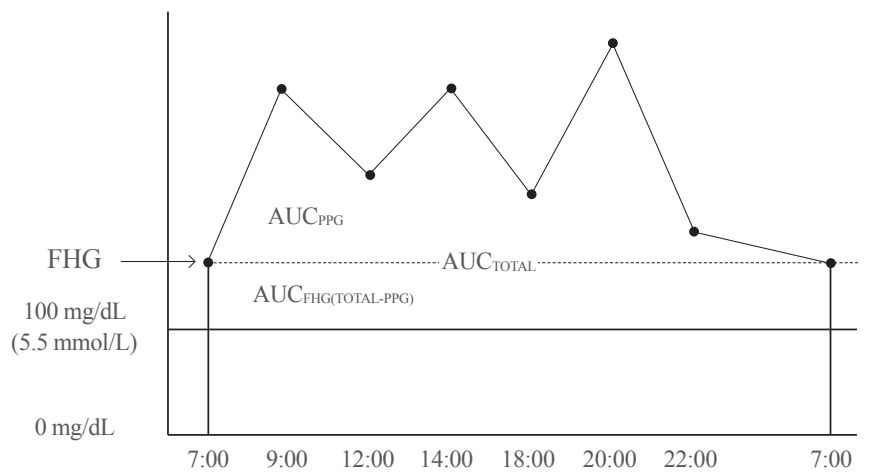

Fig. 2. The relative contributions of fasting hyperglycemia (FHG) and postprandial hyperglycemia (PPG) to overall hyperglycemia according to the tertiles of glycated hemoglobin (HbA1c). AUC, area under the curve.

performed after 12 hours of fasting. They included HbAlc, Cpeptide, high sensitivity C-reactive protein (hsCRP), total cholesterol, triglyceride (TG), high-density lipoprotein cholesterol, low-density lipoprotein cholesterol, creatinine, aspartate transaminase (AST), and alanine transaminase (ALT).

\section{Statistical analysis}

The results are presented as mean \pm standard deviation (SD) for continuous variables and as percentages for categorical variables. Moreover, graphs were plotted with mean \pm SD. We used analysis of variance (ANOVA) with the linear trend test to examine the difference between the contribution of FHG and that of PPG to overall hyperglycemia by HbA1c tertile, and the change in the contributions. Additionally, to identify the factors affecting the two types of hyperglycemia, we performed a multivariate linear regression model in which $\mathrm{AUC}_{\mathrm{PPG}}$ and $\mathrm{AUC}_{\mathrm{FHG}}$ were treated as dependent variables, while independent variables included those significantly associated with $\mathrm{AUC}_{\mathrm{PPG}}$ and $\mathrm{AUC}_{\mathrm{FHG}}$ in the simple correlation analysis and Student's $t$ test. Non-normally distributed variables were logarithmically transformed and analyzed. In this study, we used SPSS version 18.0 (SPSS Inc., Chicago, IL, USA) to analyze data and set the level of significance at $P<0.05$.

\section{RESULTS}

\section{Clinico-biochemical characteristics of patients}

This study included 194 patients with the mean age of 57.6 \pm 9.0 years old. Male patients $(n=137,69 \%)$ outnumbered female ones $(n=57,31 \%)$. Their mean duration of having diabetes was $7.6 \pm 6.7$ years, and the mean $\mathrm{HbAlc}$ as $7.0 \% \pm 0.9 \%$. Among
Table 1. Baseline Clinical and Laboratory Characteristics of the Subjects

\begin{tabular}{lc}
\hline Characteristic & Value \\
\hline Number & 194 \\
Sex, male/female & $137 / 57$ \\
\hline Age, yr & $57.6 \pm 9.0$ \\
Smoking & $70(35.9)$ \\
Height, cm & $162.0 \pm 14.3$ \\
Body weight, kg & $69.9 \pm 11.6$ \\
BMI, kg/m ${ }^{2}$ & $26.0 \pm 3.1$ \\
WC, cm & $89.7 \pm 8.3$ \\
\hline Systolic BP, mm Hg & $138.3 \pm 17.0$ \\
Diastolic BP, mm Hg & $82.2 \pm 10.0$ \\
Duration of DM, yr & $7.6 \pm 6.7$ \\
C-peptide, ng/mL & $2.2 \pm 0.9$ \\
HbAlc, $\%$ & $7.0 \pm 0.9$ \\
Creatinine, mg/dL & $1.0 \pm 0.2$ \\
hsCRP, mg/dL & $0.17 \pm 0.4$ \\
ALT, IU/L & $31.7 \pm 19.4$ \\
AST, IU/L & $26.67 \pm 12.2$ \\
TC, mg/dL & $169.5 \pm 34.1$ \\
TG, mg/dL & $128.7 \pm 80.3$ \\
HDL-C, mg/dL & $48.0 \pm 11.7$ \\
\hline LDL-C, mg/dL & $102.4 \pm 30.9$ \\
Use of sulfonylurea & $159(81.5)$ \\
Use of metformin & $112(57.4)$ \\
Use of thiazolinedione & $16(8.2)$ \\
\hline Use of DPP4i & $22(11.3)$ \\
\hline & \\
\hline &
\end{tabular}

Values are expressed as mean \pm standard deviation or number (\%). BMI, body mass index; WC, waist circumference; BP, blood pressure; DM, diabetes mellitus; HbA1c, glycated hemoglobin; hsCRP, high sensitivity C-reactive protein; ALT, alanine transaminase; AST, aspartate transaminase; TC, total cholesterol; TG, triglyceride; HDL-C, highdensity lipoprotein cholesterol; LDL-C, low-density lipoprotein cholesterol; DPP4i, dipeptidyl peptidase-4 inhibitor.

hypoglycemic agents, sulfonylurea was most commonly taken (81.5\%) followed by metformin (57.4\%), and dipeptidyl peptidase-4 inhibitor (DPP4i; 11.3\%) (Table 1).

\section{Changes in FHG and PPG, by HbA1c value}

We divided patients into three groups according to HbAlc tertiles. Then, we examined whether the contributions of FHG and PPG changed significantly by HbAlc. The mean percentage of contribution of FHG was $44.7 \pm 5.6$ in Group 1, compared to $58.0 \pm 4.4$ in Group 2 and $66.5 \pm 2.8$ in Group 3. Meanwhile, the 
Table 2. Comparisons of Percentages of Contributions of FHG and PPG between Tertiles of HbA1c

\begin{tabular}{|c|c|c|c|c|c|}
\hline & \multicolumn{3}{|c|}{ Tertiles of HbA1c } & \multirow{2}{*}{ PANOVA } & \multirow{2}{*}{$P$ TREND } \\
\hline & $\leq 6.6 \%$ & $6.7 \%-7.1 \%$ & $\geq 7.2 \%$ & & \\
\hline Contribution of FHG & $44.7 \pm 5.55$ & $58.0 \pm 4.35$ & $66.5 \pm 2.80$ & 0.002 & $<0.001$ \\
\hline Contribution of PPG & $55.3 \pm 5.55$ & $42.0 \pm 4.35$ & $33.5 \pm 2.80$ & 0.002 & $<0.001$ \\
\hline
\end{tabular}

Values are expressed as mean \pm standard deviation.

FHG, fasting hyperglycemia; PPG, postprandial hyperglycemia; HbAlc, glycated hemoglobin; $P$ ANOVA, $P$ value by analysis of variance; $P$ TREND, $P$ value by linear trend test.
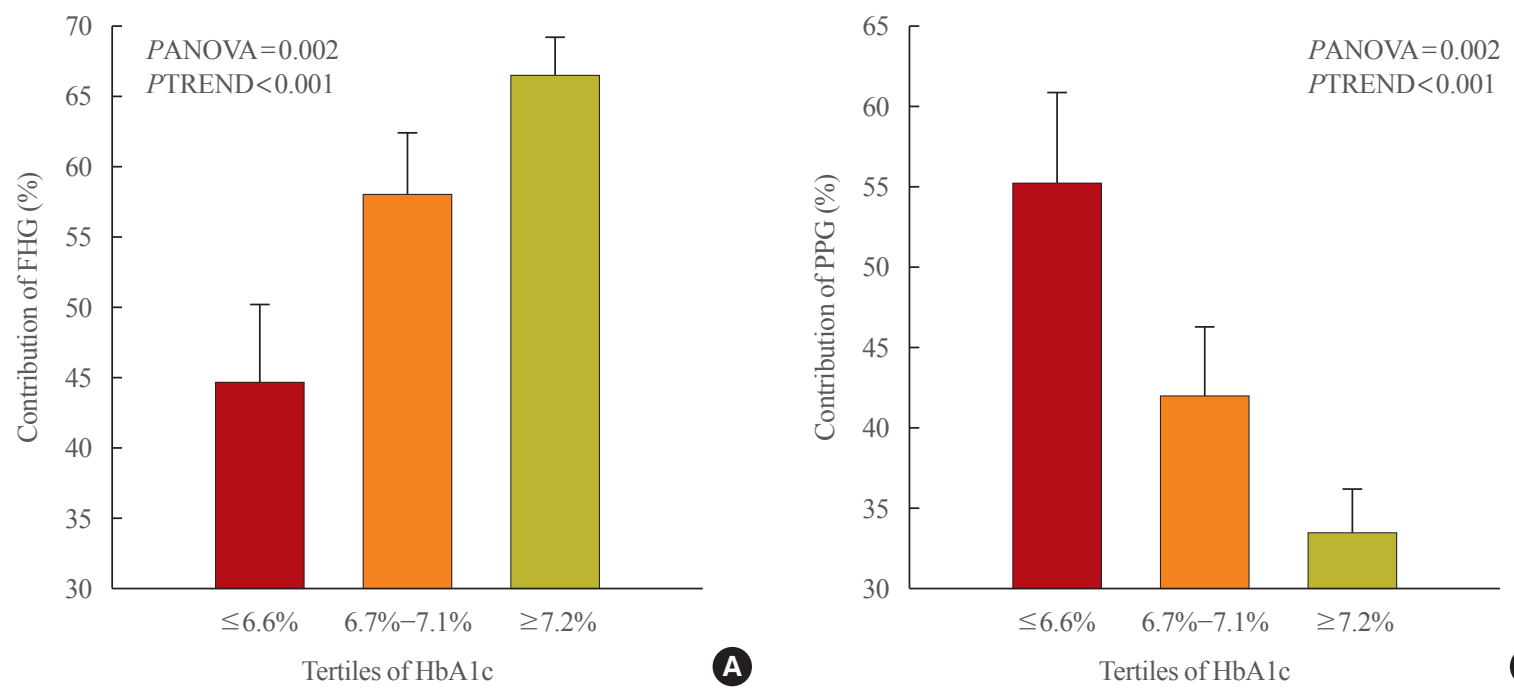

B

Fig. 3. The relative contributions of (A) fasting hyperglycemia (FHG) and (B) postprandial hyperglycemia (PPG) to overall hyperglycemia according to the tertiles of glycated hemoglobin $(\mathrm{HbA} 1 \mathrm{c})$. Data are expressed as the mean \pm standard error. $P$ ANOVA, $P$ value by analysis of variance; $P$ TREND, $P$ value by linear trend test.

figures for PPG were 55.3 \pm 5.6 in Group 1, 42.0 \pm 4.4 in Group 2, and $33.5 \pm 2.8$ in Group 3. Here, it can be seen that as HbA1c increased, the mean percentage of contribution of FHG increased $(P A N O V A=0.002, P$ TREND $<0.001)$ while that of PPG decreased $(P A N O V A=0.002, P$ TREND $<0.001)$ (Table 2 , Fig. 3).

\section{Predictors of FHG and PPG}

To identify predictors of FHG and PPG, we used univariate and multivariate models with sex, age, illness duration, medication, and certain blood test results as independent variables, and $\mathrm{AUC}_{\mathrm{FHG}}$ and $\mathrm{AUC}_{\mathrm{PPG}}$ as dependent variables. The correlation analysis and Student's $t$ test showed significant associations between $\mathrm{AUC}_{\mathrm{FHG}}$ and several factors, included age, body mass index, waist circumference, HbA1c, C-peptide, ALT, TG, and sulfonylurea use. Meanwhile, factors significantly associated with $\mathrm{AUC}_{\mathrm{PPG}}$, including age, systolic blood pressure, and duration of diabetes, HbA1c, C-peptide, hsCRP, sulfonylurea, and DPP4i use (Tables 3, 4). In the multivariate linear regression analysis, we only included factors that were significantly associated with $\mathrm{AUC}_{\mathrm{FHG}}$ and $\mathrm{AUC}_{\mathrm{PPG}}$ in the univariate analysis. In this analysis, besides $\mathrm{HbA1c}(\beta=0.615, P<0.001)$, only waist circumference $(\beta=0.216, P=0.042)$ and TG $(\beta=0.121, P=0.048)$ were associated with $\mathrm{AUC}_{\mathrm{FHG}}$. Apart from HbA1c $(\beta=0.231, P=0.002)$, only age showed a significant association with $\mathrm{AUC}_{\mathrm{PPG}}(\beta=$ 0.196, $P=0.009$ ) (Table 5).

\section{DISCUSSION}

This study assessed not only the contribution of FHG and PPG to overall hyperglycemia but also the factors affecting these two types of hyperglycemia.

Many studies have been conducted on the contributions of fasting or PPG to overall blood glucose control; nevertheless, their results were found to be inconsistent. Monnier et al. [4] reported that the relative contributions of FHG and PPG differed 
Table 3. Simple Correlations between the AUC of PPG and FHG and Continuous Variables in the Subjects

\begin{tabular}{|c|c|c|c|c|}
\hline \multirow{2}{*}{ Variable } & \multicolumn{2}{|c|}{$\mathrm{AUC}_{\mathrm{FHG}}$} & \multicolumn{2}{|c|}{$\mathrm{AUC} \mathrm{CPG}_{\mathrm{PP}}$} \\
\hline & $r$ & $P$ value & $r$ & $P$ value \\
\hline Age & -0.146 & 0.042 & 0.191 & 0.008 \\
\hline BMI & 0.152 & 0.035 & 0.117 & 0.105 \\
\hline Waist circumference & 0.185 & 0.010 & 0.123 & 0.009 \\
\hline Systolic BP & 0.092 & 0.202 & 0.185 & 0.010 \\
\hline Diastolic BP & 0.078 & 0.282 & 0.060 & 0.406 \\
\hline Duration of diabetes & 0.093 & 0.199 & 0.185 & 0.010 \\
\hline HbA1c & 0.658 & $<0.001$ & 0.282 & $<0.001$ \\
\hline C-peptide & 0.217 & 0.002 & 0.198 & 0.006 \\
\hline hsCRP & -0.043 & 0.549 & 0.145 & 0.043 \\
\hline ALT & 0.228 & 0.001 & 0.047 & 0.516 \\
\hline AST & 0.132 & 0.067 & 0.131 & 0.070 \\
\hline Creatinine & -0.070 & 0.330 & 0.096 & 0.182 \\
\hline Total cholesterol & 0.073 & 0.309 & -0.081 & 0.264 \\
\hline Triglyceride & 0.278 & $<0.001$ & 0.080 & 0.268 \\
\hline HDL-C & 0.007 & 0.924 & -0.119 & 0.098 \\
\hline LDL-C & 0.000 & 0.886 & -0.063 & 0.384 \\
\hline
\end{tabular}

$P$ values are calculated using the Pearson's correlation analysis.

AUC, area under the curve; PPG, postprandial hyperglycemia; FHG, fasting hyperglycemia; $r$, Pearson's correlation coefficient; BMI, body mass index; BP, blood pressure; HbAlc, glycated hemoglobin; hsCRP, high sensitivity C-reactive protein; ALT, alanine transaminase; AST, aspartate transaminase; HDL-C, high-density lipoprotein cholesterol; LDL-C, low-density lipoprotein cholesterol.

by the progression of diabetes. To assess these contributions, they categorized patients into different groups based on $\mathrm{HbAlc}$ tertiles and calculated the AUC. We based on their methods to analyze data of Korean patients; however, our study differed from theirs in several respects [4]. First, the number of patients in our study was small $(n=194)$; therefore, we divided patients into three groups according to $\mathrm{HbA} 1 \mathrm{c}$ tertiles instead of five groups as categorized by Monnier et al. [4]. Second, to have more accurate calculation of the areas and contributions, we selected patients who measured their own blood glucose at 7 points of time during the day (i.e., immediately before each meal, 2 hours after each meal, and before sleeping), compared to 4 points of time as mentioned in the study by Monnier et al. [4]. Third, Monnier et al. [4] calculated AUC total $_{\text {with the cut-off }}$ point of $6.1 \mathrm{mmol} / \mathrm{L}(110 \mathrm{mg} / \mathrm{dL})$, compared to $5.5 \mathrm{mmol} / \mathrm{L}$ $(100 \mathrm{mg} / \mathrm{dL})$ in our present study (To use this cut-off point, we referred to the American Diabetes Association's upper limit of the normal fasting glucose) [6]. Finally, patients in our present
Table 4. Differences in the AUC of FHG and PPG According to Categorical Variables in the Subjects

\begin{tabular}{|c|c|c|c|c|}
\hline Variable & $\mathrm{AUC}_{\mathrm{FHG}}$ & $P$ value & $\mathrm{AUC}_{\mathrm{PPG}}$ & $P$ value \\
\hline Sex & & 0.517 & & 0.963 \\
\hline Male & $848.2 \pm 50.2$ & & $552.8 \pm 38.1$ & \\
\hline Female & $789.3 \pm 72.6$ & & $556.1 \pm 57.6$ & \\
\hline Smoking & & 0.765 & & 0.819 \\
\hline Yes & $786.7 \pm 75.5$ & & $553.4 \pm 55.6$ & \\
\hline No & $814.4 \pm 56.8$ & & $569.7 \pm 45.5$ & \\
\hline Sulfonylurea & & 0.009 & & $<0.001$ \\
\hline Use & $924.7 \pm 55.8$ & & $649.3 \pm 46.4$ & \\
\hline Non-use & $701.2 \pm 61.8$ & & $428.7 \pm 37.6$ & \\
\hline Metformin & & 0.546 & & 0.438 \\
\hline Use & $844.8 \pm 44.6$ & & $570.3 \pm 35.6$ & \\
\hline Non-use & $774.8 \pm 123.6$ & & $501.4 \pm 78.3$ & \\
\hline Thiazolidinedione & & 0.122 & & 0.780 \\
\hline Use & $1,045.1 \pm 174.9$ & & $529.1 \pm 115.4$ & \\
\hline Non-use & $810.2 \pm 43.0$ & & $561.7 \pm 33.6$ & \\
\hline DPP4i & & 0.071 & & 0.032 \\
\hline Use & $620.1 \pm 86.7$ & & $368.0 \pm 63.2$ & \\
\hline Non-use & $857.5 \pm 45.9$ & & $583.9 \pm 35.1$ & \\
\hline
\end{tabular}

Values are expressed as mean \pm standard deviation. $P$ values are calculated using Student's $t$ test.

AUC, area under the curve; FHG, fasting hyperglycemia; PPG, postprandial hyperglycemia; DPP4i, dipeptidyl peptidase-4 inhibitor.

study had better blood glucose control than those in the study by Monnier et al. [4], as the mean HbAlc value in our study was lower $(7.0 \%$ vs. $8.8 \%)$. Despite these differences, both studies shared the same result that the contribution of FHG increased and that of PPG decreased as HbAlc increased. This result was consistent with that of a study by Kikuchi et al. [7] and that of another study by Wang et al. [8]. Kikuchi et al. [7] conducted a study to assess the correlation between AUC and HbAlc in Japanese T2DM patients, but not the contributions of FHG and PPG. Their study results, however, pointed out that postprandial and fasting glucose were significantly associated with $\mathrm{HbA1c}$ in groups with better and poorer blood glucose control, respectively. In 2011, Wang et al. [8] categorized participants into five groups by $\mathrm{HbA} 1 \mathrm{c}$ in a similar manner as the present study to assess the contributions of FHG and PPG among Asian T2DM patients. Like our study results, theirs also showed that the contribution of PPG tended to increase in the group with low $\mathrm{HbAlc}$ and FHG in the group with high HbA1c.

Unlike previous research, this study also analyzed factors 
Table 5. Multiple Regression Analysis to Identify the Factors Associated with FHG and PPG

\begin{tabular}{llcc}
\hline Dependent variable & Independent variable & $\beta$ & $P$ value \\
\hline $\mathrm{AUC}_{\mathrm{FHG}}\left(R^{2}=0.436\right)$ & HbA1c & 0.615 & $<0.001$ \\
& Age & -0.068 & 0.222 \\
& Sex & -0.011 & 0.854 \\
& Basal C-peptide & 0.026 & 0.699 \\
& Waist circumference & 0.216 & 0.042 \\
& BMI & -0.168 & 0.096 \\
& Triglyceride & 0.121 & 0.048 \\
& ALT & 0.031 & 0.597 \\
& Sulfonylurea & 0.036 & 0.533 \\
AUC PPG $^{2}\left(R^{2}=0.161\right)$ & HbA1c & 0.231 & 0.002 \\
& Age & 0.196 & 0.009 \\
& Sex & 0.060 & 0.400 \\
& Systolic BP & 0.084 & 0.265 \\
& Duration of DM & 0.056 & 0.481 \\
C-peptide & 0.072 & 0.358 \\
hsCRP & 0.117 & 0.100 \\
Sulfonylurea & 0.094 & 0.257 \\
DPP4i & -0.132 & 0.088 \\
\hline
\end{tabular}

FHG, fasting hyperglycemia; PPG, postprandial hyperglycemia; $\beta$, corrected regression coefficient; AUC, area under the curve; HbAlc, glycated hemoglobin; BMI, body mass index; ALT, alanine transaminase; $\mathrm{BP}$, blood pressure; DM, diabetes mellitus; hsCRP, high sensitivity Creactive protein; DPP4i, dipeptidyl peptidase-4 inhibitor.

other than HbA1c that might affect FHG and PPG. When controlling for $\mathrm{HbAlc}$ and other factors, FHG showed a significant correlation with TG and waist circumference. It has been suggested in previous studies that TG and waist circumference increased fasting glucose by affecting insulin resistance. In 2002, Kametani et al. [9] followed-up patients for 9 years and found that obesity, hypertension, hypertriglyceridemia, and family history of diabetes were significant risk factors of impaired fasting glucose. Furthermore, in 2013, Lin et al. [10] reported that the risk of impaired fasting glucose increased with heightened levels of TG. However, most previous studies showed that obesity and hypertriglyceridemia were factors related to impaired fasting glucose. Unlike our study, they did not thoroughly assess the effects of TG or waist circumference on fasting glucose in patients with diabetes.

Apart from $\mathrm{HbA1c}$, age was the only factor affecting PPG. The correlation between hyperglycemia and age has been previously reported [11]. In 2013, Munshi et al. [12] analyzed the fasting and postprandial contribution to overall hyperglycemia using the AUC method. They found that in higher age groups, the contribution of postprandial glucose was greater than that of fasting glucose. Chiu et al. [13] explained that as age increases, the functions of beta-cells decrease, resulting in the relative rise in the contribution of postprandial glucose.

Based on the results of this study, we provided the following recommendations for the treatment of patients with diabetes. First, the contribution of PPG is generally higher in well-controlled patients; therefore, it is difficult to reach the target $\mathrm{HbA} 1 \mathrm{c}$ by reducing only fasting glucose levels. In a previous study by Woerle et al. [14], patients who reached the target $\mathrm{HbA} 1 \mathrm{c}$ of below $7.0 \%$ had a significantly lower postprandial glucose level than that of those who did not. However, the study also showed no differences in the fasting glucose level. As the relative contribution changes with the degree of glycemic control, medications should be prescribed accordingly. Second, medication must be selected considering the age even if the $\mathrm{HbAlc}$ is the same, as the relative contribution of PPG increases with age which is typically accompanied by the decreased secretion of insulin. Third, the contribution of FHG is high in patients with obesity or high levels of TG. The use of drug that usually reduces fasting glucose level, such as metformin and thiazolidinedione, should therefore be considered with priority.

This study encountered some limitations that should be addressed. The first limitation was the retrospective nature of this study. Second, the number of patients $(n=194)$ was relatively small compared to that of the previous study conducted by Monnier et al. [4]. Third, the patients in this present study had relatively good control of their blood glucose, which was reflected in their relatively low $\mathrm{HbA} 1 \mathrm{c}$ levels. When using tertiles to categorize the study sample into different groups, the group with the poorest control of blood glucose showed a mean $\mathrm{HbAlc}$ of $8 \%$. Therefore, it remains unclear whether the results of our study apply to patients with poor blood glucose control. However, our results of high contribution of fasting glucose in higher $\mathrm{HbAlc}$ levels and high contribution of postprandial glucose in lower HbAlc levels are consistent with the results of studies outside Korea that include patients with various levels of blood glucose control $[4,5,7,8,14]$. Thus, we can predict similar results from Korean patients with poor glucose control. Fourth, our study calculated the contribution of FHG and PPG using 7-point SMBG instead of continuous glucose monitoring (CGM). Most international studies that have shown proportional relationship between contribution of FHG and HbAlc used 4-point or 7-point SMBG [4,5,7,12,14-16]. Thus, we also used 
the same method and validated that the contribution of FHG is high at higher levels of HbAlc in Korean diabetes patients. However, as measuring blood glucose using CGM can more accurately differentiate fasting and postprandial glucose than using SMBG, detailed studies assessing the contribution of FHG and PPG in Korean patients using CGM are further required. None the less, this present study made certain contributions to the current literature, as it, to our best knowledge, is the first to use 7-point SMBG in Korean T2DM patients to examine the research topic of interest.

This study assessed the contributions of FHG and PPG in 194 Korean T2DM patients and analyzed data of three HbA1c groups. The contribution of PPG was high in the group with relatively good control of blood glucose, whereas that of FHG gradually increased with elevated HbA1c. Two other factors, namely waist circumference and TG, were also significantly associated with FHG. However, apart from HbAlc, age was the only factor that had a statistically significant association with PPG.

\section{CONFLICTS OF INTEREST}

No potential conflict of interest relevant to this article was reported.

\section{ACKNOWLEDGMENTS}

This research was supported by the 2020 scientific promotion program funded by Jeju National University.

\section{AUTHOR CONTRIBUTIONS}

Conception or design: G.K. Acquisition, analysis, or interpretation of data: J.M., J.Y.K., S.Y., G.K. Drafting the work or revising: J.M., J.Y.K. Final approval of the manuscript: G.K.

\section{ORCID}

Jaecheol Moon https://orcid.org/0000-0002-6617-6477

Ji Young Kim https://orcid.org/0000-0003-1016-9902

Gwanpyo Koh https://orcid.org/0000-0002-6020-2777

\section{REFERENCES}

1. Avignon A, Radauceanu A, Monnier L. Nonfasting plasma glucose is a better marker of diabetic control than fasting plas- ma glucose in type 2 diabetes. Diabetes Care 1997;20:1822-6.

2. Rohlfing CL, Wiedmeyer HM, Little RR, England JD, Tennill A, Goldstein DE. Defining the relationship between plasma glucose and $\mathrm{HbA}(1 \mathrm{c})$ : analysis of glucose profiles and $\mathrm{HbA}(1 \mathrm{c})$ in the Diabetes Control and Complications Trial. Diabetes Care 2002;25:275-8.

3. Bonora E, Calcaterra F, Lombardi S, Bonfante N, Formentini G, Bonadonna RC, et al. Plasma glucose levels throughout the day and $\mathrm{HbA}(1 \mathrm{c})$ interrelationships in type 2 diabetes: implications for treatment and monitoring of metabolic control. Diabetes Care 2001;24:2023-9.

4. Monnier L, Lapinski H, Colette C. Contributions of fasting and postprandial plasma glucose increments to the overall diurnal hyperglycemia of type 2 diabetic patients: variations with increasing levels of $\mathrm{HbA}(1 \mathrm{c})$. Diabetes Care 2003;26: 881-5.

5. Riddle M, Umpierrez G, DiGenio A, Zhou R, Rosenstock J. Contributions of basal and postprandial hyperglycemia over a wide range of $\mathrm{A} 1 \mathrm{C}$ levels before and after treatment intensification in type 2 diabetes. Diabetes Care 2011;34:2508-14.

6. American Diabetes Association. Standards of medical care in diabetes. Diabetes Care 2004;27 Suppl 1:S15-35.

7. Kikuchi K, Nezu U, Shirakawa J, Sato K, Togashi Y, Kikuchi $\mathrm{T}$, et al. Correlations of fasting and postprandial blood glucose increments to the overall diurnal hyperglycemic status in type 2 diabetic patients: variations with levels of HbA1c. Endocr J 2010;57:259-66.

8. Wang JS, Tu ST, Lee IT, Lin SD, Lin SY, Su SL, et al. Contribution of postprandial glucose to excess hyperglycaemia in Asian type 2 diabetic patients using continuous glucose monitoring. Diabetes Metab Res Rev 2011;27:79-84.

9. Kametani T, Koshida H, Nagaoka T, Miyakoshi H. Hypertriglyceridemia is an independent risk factor for development of impaired fasting glucose and diabetes mellitus: a 9-year longitudinal study in Japanese. Intern Med 2002;41:516-21.

10. Lin SX, Berlin I, Younge R, Jin Z, Sibley CT, Schreiner P, et al. Does elevated plasma triglyceride level independently predict impaired fasting glucose?: the Multi-Ethnic Study of Atherosclerosis (MESA). Diabetes Care 2013;36:342-7.

11. Bando Y, Ushiogi Y, Okafuji K, Toya D, Tanaka N, Fujisawa $\mathrm{M}$. The relationship of fasting plasma glucose values and other variables to 2-h postload plasma glucose in Japanese subjects. Diabetes Care 2001;24:1156-60.

12. Munshi MN, Pandya N, Umpierrez GE, DiGenio A, Zhou R, Riddle MC. Contributions of basal and prandial hyperglycemia to total hyperglycemia in older and younger adults with 
type 2 diabetes mellitus. J Am Geriatr Soc 2013;61:535-41.

13. Chiu KC, Lee NP, Cohan P, Chuang LM. Beta cell function declines with age in glucose tolerant Caucasians. Clin Endocrinol (Oxf) 2000;53:569-75.

14. Woerle HJ, Neumann C, Zschau S, Tenner S, Irsigler A, Schirra J, et al. Impact of fasting and postprandial glycemia on overall glycemic control in type 2 diabetes Importance of postprandial glycemia to achieve target $\mathrm{HbA1c}$ levels. Diabetes Res Clin Pract 2007;77:280-5.
15. Schernthaner G, Guerci B, Gallwitz B, Rose L, Nicolay C, Kraus $\mathrm{P}$, et al. Impact of postprandial and fasting glucose concentrations on $\mathrm{HbAlc}$ in patients with type 2 diabetes. Diabetes Metab 2010;36:389-94.

16. Monnier L, Colette C, Dunseath GJ, Owens DR. The loss of postprandial glycemic control precedes stepwise deterioration of fasting with worsening diabetes. Diabetes Care 2007; 30:263-9. 